Revista lus et Praxis, Año 16, No 1, 2010, pp. 171 - 196

ISSN 0717 - 2877

"La externalización laboral y la cesión ilegal de trabajadores en el sistema jurídico chileno"

Irene Rojas Miño

\title{
LA EXTERNALIZACIÓN LABORAL Y LA CESIÓN ILEGAL DE TRABAJADORES EN EL SISTEMA JURÍDICO CHILENO*
}

\author{
LABOR OUTSOURCING AND ILLEGAL CESSION OF WORKERS
}

AT THE CHILEAN LAW SYSTEM

IRENE RoJAS MiÑO**

\begin{abstract}
RESUMEN
Este trabajo identifica a la cesión ilegal de trabajadores como manifestación ilícita de la externalización laboral. A la vez, analiza la configuración de la cesión ilegal de trabajadores en el ordenamiento jurídico chileno, sus concretos efectos jurídicos y, además, un particular problema que se ha planteado con la eficacia de la norma jurídica que establece este ilícito laboral.
\end{abstract}

\section{ABSTRACT}

This work identifies the illegal cession of workers, as the illicit manifestation of the labor outsourcing. At the same time, it analyzes the illegal cession of workers configuration at the chilean law system, its specifics legal effects and a particular problem derived of the efficiency of the law that establishes this labor illicit.

Palabras Clave

Empresa, Externalización Laboral, Subcontratación Laboral, Suministro de Trabajo

KEY WORDS

Enterprise, Labor Outsourcing, Labor Subcontracting, Work Supply

\footnotetext{
* Este trabajo ha sido elaborado en el marco del Proyecto de Investigación de la Dirección de Investigación de la Universidad de Talca, "E000142", denominado "La externalización de las actividades laborales en las empresas: subcontratación y suministro de trabajo. Sus efectos jurídicos en las relaciones de trabajo". Asimismo, es también resultado del Proyecto Conjunto de Investigación A/9594/07 "La Descentralización Productiva en el Derecho del Trabajo Español y Chileno: Análisis Comparado de la normativa en materia de Cesión de Trabajadores, Contratas y Subcontratas de Obras y servicios y Transmisión de Empresa", realizado entre el Departamento de Derecho del Trabajo de la Universidad Complutense de Madrid y el Área de Derecho del Trabajo de la Universidad de Talca, en el marco del Programa de Cooperación Interuniversitaria e Investigación Científica entre España e Iberoamérica. Trabajo recibido el 21 de octubre de 2009 y aprobado el 30 de marzo de 2010.

** Profesora de Derecho del Trabajo, Universidad de Talca; Doctora en Derecho, Universidad de Valencia, España. Correo electrónico: irojas@utalca.cl.
} 


\section{INTRODUCCIÓN}

Si bien las manifestaciones de la externalización laboral han sido asumidas por los diversos ordenamientos jurídicos laborales, éstos han establecido específicas exigencias para que operen de forma lícita al interior de los respectivos sistemas jurídicos. En efecto, dichos requisitos han sido planteados por los problemas que en la actualidad presentan los efectos de la descentralización productiva en los distintos sistemas de relaciones laborales, en cuanto muchos de los tradicionales instrumentos jurídicos laborales se muestran ineficaces para el objetivo de regular las relaciones de trabajo y tutelar los derechos de los trabajadores.

La externalización laboral, como manifestación de la descentralización productiva, comprende tanto a la subcontratación como al suministro de trabajo. La primera ha sido aceptada por el Derecho del Trabajo desde sus orígenes, aunque en nuestro sistema jurídico entonces sólo se establecieron específicas medidas a fin de limitar uno de los riesgos que plantea para el ejercicio de los derechos laborales'. El suministro de trabajo, por su parte, sólo ha sido admitido en los últimos años; siguiendo con ello una tendencia universal manifestada por los diversos sistemas jurídicos. Dado que el suministro de trabajo es un fenómeno de las relaciones económicas y laborales que se plantea sólo en las últimas décadas, los sistemas jurídicos presentaron resistencia para su reconocimiento, dado, de un lado, que modifica el concepto tradicional de relación laboral individual de trabajo, constituida por dos partes, el empleador y el trabajador; y del otro, por su incidencia en la precarización laboral, manifestada principalmente por puestos de trabajo de carácter temporal y de existencia de regímenes laborales diversos que se aplican al interior de una misma unidad económica: uno definido para los trabajadores de la empresa usuaria y otro para los trabajadores suministrados, siendo normalmente más desventajoso para estos últimos.

Una figura que suele confundirse con las anteriores es la de la cesión ilegal de trabajadores, en cuanto plantea una externalización que no cumple los requisitos de las manifestaciones admitidas por el ordenamiento jurídico, y cuyo estudio en el sistema chileno plantea mayores desafíos, dado su incorporación residual en la ley laboral. En efecto, tanto la subcontratación laboral como el suministro de trabajo que cumplan las exigencias establecidas por la ley, son manifestaciones lícitas de la descentralización productiva, al menos en nuestro ordenamiento jurídico y ello independientemente de las críticas políticas jurídicas que se le puedan otorgar, dadas las carencias que manifiesta su actual régimen jurídico.

La cesión ilegal de trabajadores, por su parte, se configura como otra manifestación de la descentralización productiva pero que es de carácter ilícita, en cuanto sólo simula una externalización lícita o no cumple las exigencias que la ley ha declarado esenciales para ellas, tal como sucede con la seudo subcon-

${ }^{1}$ Como fue la definición de una responsabilidad subsidiaria de la empresa que encarga la obra. 
tratación laboral, que encubre una interposición de trabajo, o con el suministro de trabajo destinado a actividades no autorizadas por ley, entre otros casos.

El Derecho Comparado, en general, ha identificado expresamente esta figura residual como "cesión ilegal de trabajadores" ${ }^{2}$. Sin embargo, no sucede lo mismo en nuestra ley laboral, la que si bien establece el tipo de "cesión ilegal de trabajadores", no lo identifica como tal, permaneciendo como versión ilícita de las manifestaciones de subcontratación laboral y de suministro de trabajo; lo que ha llevado a múltiples confusiones, tanto de carácter política-laboral como también jurídicas.

Este trabajo pretende identificar el tipo ilícito de dichas manifestaciones de la externalización laboral al interior del ordenamiento jurídico vigente y ello a partir del otorgamiento de la denominación que tiene tanto en el Derecho Internacional del Trabajo, como en el Derecho Comparado. A la vez, analizar la configuración de la cesión ilegal de trabajadores, sus concretos efectos jurídicos y, además, un particular problema que se ha planteado con la eficacia de la norma jurídica que establece este ilícito laboral.

Para la realización de este estudio, se ha recurrido tanto a fuentes normativas, en las cuales se incluye la Historia de la Ley que se trate, y a fuentes bibliográficas. También se ha acudido a la doctrina jurisprudencial, tanto en su calidad de fuente normativa, dada su incidencia en la construcción de los respectivos regímenes de descentralización productiva ${ }^{3}$, como para el conocimiento de la aplicación del ordenamiento jurídico. Al efecto, se ha pretendido mantener el nivel de rigurosidad en el análisis de esta fuente jurídica ${ }^{4}$.

\footnotetext{
${ }^{2}$ Véase, por todos, el ordenamiento jurídico español, el artículo 43 del Estatuto de los Trabajadores, referido, precisamente a la "cesión de trabajadores".

${ }^{3}$ Ciertamente, las sentencias de los tribunales de justicia no constituyen jurisprudencia en el sentido estricto, toda vez que, como regla general, no constituyen derecho en nuestro sistema jurídico. Pero sí generan doctrina de carácter jurisprudencial los fallos de los tribunales superiores de justicia y, además, constituyen fuente de conocimiento en la aplicación del derecho.

${ }^{4} \mathrm{Al}$ efecto se ha fijado un universo de estudio: se han considerado las sentencias de los Tribunales de Justicia -es decir, los Juzgados del trabajo y los Juzgados Civiles con competencia en lo Laboral, las Cortes de Apelaciones del país y la Corte Suprema-, que hayan sido publicadas a partir del año 1990 en las revistas especializadas, a saber, Revista de Derecho y Jurisprudencia, Revista Fallos del Mes, Revista Gaceta Jurídica y Revista Laboral Chilena. A este universo de estudio se plantean dos excepciones: Primero, dado que no todas las sentencias de los tribunales superiores se publican, se han incorporado, además, las sentencias dictadas por la Corte Suprema, a través de la Cuarta Sala, a partir del año 2000 (a este efecto, se han revisado en Biblioteca de la Corte Suprema todos los fallos dictado por la Sala laboral, a partir del año indicado, con posterioridad, se han revisado dichos fallos en la página web del Poder Judicial, toda vez que a partir del 1 de enero de 2007, dichos fallos son publicados en dicha página; sin embargo, en dicho período también se ha recurrido a la fuente de la Biblioteca de la C.S., pues sus antecedentes también comprenden los respectivos fallos de instancia y de apelación, cuando proceda, cuestión que no ocurre con los fallos del sistema informatizado del Poder Judicial). Segundo, además, existen sentencias dictadas fuera del universo definido que han tenido gran relevancia y han definido una doctrina jurisprudencial, como son, entre otras las pronunciadas por la Tercera Sala de la Corte Suprema sobre recurso de protección a propósito de la subcontratación laboral, por lo cual también se les incorpora en el estudio.
} 


\section{ANteCedentes de LA CESIÓN ILEGAl DE tRABAjadores}

Son cuatro los antecedentes que deben considerarse para el análisis de la cesión ilegal de trabajadores: (1) Su confusión con las formas legales de externalización. (2) La magnitud de la externalización laboral en Chile. (3) El régimen jurídico de la subcontratación laboral y (4) El régimen jurídico del suministro de trabajo.

\section{Su confusión con las formas legales de externalización}

La cesión ilegal de trabajadores plantea, básicamente, dos supuestos de configuración: en primer lugar, la simulación del empleador en la relación laboral, haciendo aparecer como tal a otro sujeto y, en segundo término, el no cumplimiento de exigencias de las formas de externalización que el sistema jurídico plantea como esenciales.

El primer supuesto es el que requiere mayor análisis. En efecto, la relación laboral individual presenta dos partes: el empleador y el trabajador, el primero dirige la actividad laboral, recibe la prestación de servicios y es titular de las respectivas obligaciones laborales; el trabajador, por su parte, se sujeta a la organización laboral que dirige el empleador, presta el servicio y es titular de los respectivos derechos. En la cesión ilegal se plantea un empleador que supuestamente responde de las obligaciones laborales pero quien dirige la actividad laboral y recibe la prestación laboral es otro sujeto, quien es el empleador real, constituyendo el primero, sólo un empleador aparente. Ciertamente que esta figura corresponde a una manifestación patológica de la descentralización productiva y, por ello mismo, es que está expresamente prohibida en diversos sistemas jurídicos. Sin embargo el problema que se presenta en las relaciones económicas y laborales es que esta la cesión ilegal se presenta como otro tipo de manifestación de externalización laboral, la que supuestamente sí está en conformidad al ordenamiento jurídico que se trate.

Es el caso de la subcontratación laboral, que siendo un negocio jurídico lícito en cuanto se trata de la contratación de una obra o servicio, puede encubrir acuerdo de suministro de mano de obra, por lo que deja de ser legal.

\subsection{La magnitud de la externalización laboral en Chile}

Un antecedente relevante es la cuantificación de la externalización laboral. Si bien existen algunos estudios empíricos que dan cuenta del fenómeno ${ }^{5}$, especial relevancia tiene la Encuesta Laboral de la Dirección del Trabajo,

${ }^{5}$ ECheverría T., M. y otros, "El otro trabajo: el suministro de personas en las empresas", Cuaderno de Investigación № 7, Dirección del Trabajo, Santiago, 2001. 
conocida como Encla ${ }^{6}$, que se aplica a partir del año 1998. La Encla del año 2006, de acuerdo con la metodología definida ${ }^{7}$-específicamente, de acuerdo a la información otorgada por los empleadores en las empresas-, plantea que un $41,2 \%$ de las empresas subcontrata actividades a terceros ${ }^{8}$. Esta información sobre subcontratación plantea diversas peculiaridades. Primero, el grueso de la subcontratación se presenta desde la gran y mediana empresa, toda vez que un 68,3 de las primeras efectúan subcontratación, y un 58,7\% de las segundas 9 . Segundo, una parte importante de la subcontratación es relativa a la actividad principal de la empresa, específicamente un 32,6\%.

Además, se ha verificado un rápido aumento de la subcontratación, tal como lo muestra el sector de la minería. En efecto, de acuerdo con información elaborada por la Dirección del Trabajo, a partir de los Anuarios de la Minería en Chile ${ }^{10}$, al año 2004 del total de trabajadores ocupados en dicho sector -un total de 112.461-el $61 \%$ dependía de empresas subcontratistas, mientras que sólo el 39\% lo hacía de empresas mandantes. Sin embargo, esta situación es relativamente nueva: sólo a partir del año 1982 se registran trabajadores del sector laborando en empresas contratistas de la minería, pero su cuantía en ese año sólo significa el 0,5\% ${ }^{11}$.

Respecto al suministro de trabajo, la Encla del año 2006 plantea que este sólo comprende al 5,7 de los trabajadores asalariados, es decir, alrededor de

\footnotetext{
${ }^{6}$ Y que a la fecha (septiembre de 2009) plantea registro de cinco años: 1998, 1999 y 2002, 2004 y 2006. Dirección del Trabajo, Departamento de Estudios: de 1998 ("Encla 98 Informe de Resultados Regiones", Santiago de Chile, 1999), de 1999 ("Encla 99 Informe de Resultados", Santiago de Chile, 2000), de 2002 ("Encla 2002 Informe de Resultados", Santiago de Chile, septiembre de 2003), de 2004 ("Encla 2004, Cuarta Encuesta Laboral, Informe de Resultados", Santiago de Chile, septiembre de 2005) y de 2006 ("Encla 2006, Informe de Resultados, Quinta Encuesta Laboral", Santiago de Chile, octubre de 2007).
}

${ }^{7}$ De acuerdo a lo informado en lo relativo a los aspectos metodológicos (Encla 2006, cit. nota n. 6, pp. 5-6), en esta encuesta es la empresa la que constituye la unidad de análisis, las que son seleccionadas de acuerdo a un procedimiento muestral adecuado. En ellas Encla utiliza diversas fuentes de información para dar cuenta de los diversos temas que cubre la encuesta: Estas fuentes provienen de la aplicación de un cuestionario autoadministrado a los empleadores y de entrevistas con informantes calificados al interior de la empresa. Entre estos últimos están los dirigentes de la organización sindical que exista al interior de la empresa, con quienes se contrasta la información dada por la parte empresarial. Si en dicha empresa no existe tal organización se elige al azar a un trabajador de dicha empresa de acuerdo a un procedimiento preestablecido y en base a un cuestionario especialmente diseñado para estos efectos.

${ }^{8}$ Encla 2006, cit. nota n. 6, pp. 31 y ss.

${ }_{9}^{9}$ Mientras que lo efectúa sólo un 40,7 de la pequeña empresa y un $27 \%$ de la microempresa. Véase Encla 2007, cit. nota n. 6, pp. 32 y ss.

${ }^{10}$ En, Echeverría, M., "Los Riesgos Laborales de la subcontratación", Aporte al Debate Laboral № 19, Departamento de Estudios de la Dirección del Trabajo, Santiago, abril de 2006. Dicho registro lo hace el Servicio Nacional de Geología y Minería, del que se da cuenta en este estudio de M. Echeverría.

${ }^{11}$ Echeverría, "Los Riesgos", cit. nota n. 10, p. 48. 
197.000 trabajadores $^{12}$. A la vez, sólo el 10\% de las empresas emplea trabajadores suministrados. En todo caso, dede considerarse en estos datos que la información está otorgada en el período previo a la entrada en vigencia de la Ley $\mathrm{N}^{\circ} 20.123$, que fue la que reconoció al suministro de trabajo como una forma lícita de externalización laboral; por lo que podría haberse planteado un ocultamiento de parte de las cifras.

\section{Régimen jurídico de la subcontratación laboral}

\section{a) Antecedentes}

Si bien el sistema jurídico chileno ha admitido la subcontratación laboral desde el primer modelo normativo laboral, es decir, el del Código del Trabajo de 1931, esta regulación se limitaba a establecer la responsabilidad subsidiaria del empleador principal. El actual régimen jurídico, es el que estableció la Ley $N^{\circ} 20.123^{13}$, la que entró en vigencia el pasado 14 de enero de 2007.

Esta nueva normativa legal reguló cuatro materias del trabajo en régimen de subcontratación: En primer lugar, definió los elementos de configuración de la subcontratación laboral. En segundo término, estableció el efecto de la imputación de la relación laboral a la empresa principal en el supuesto de que se encubra una cesión ilegal de trabajadores. En tercer lugar, definió un régimen de responsabilidad solidaria, que bajo el cumplimiento de específicas exigencias pasaría a ser subsidiaria. Y en cuarto lugar, estableció una obligación directa de la empresa principal en materia de higiene y seguridad.

\section{b) Configuración de la subcontratación laboral}

A través del instrumento de la definición' ${ }^{14}$, la ley estableció los elementos que configuran la subcontratación laboral: de un lado, el objeto de la subcontra-

\footnotetext{
${ }^{12}$ Encla 2006, cit. nota n. 6, pp. 37 y ss.

${ }^{13}$ Publicada el 16 de octubre de 2006. Al efecto, la Ley $N^{\circ} 20.123$ introdujo un nuevo Título VII al Libro Primero del Código del Trabajo, el que distingue entre un Párrafo $1^{\circ}$ "Del trabajo en régimen de subcontratación" y un Párrafo $2^{\circ}$ "De las empresas de servicios transitorios, del contrato de puesta a disposición de trabajadores y del contrato de trabajo de servicios transitorios".

${ }^{14}$ Art. 183-A, primera parte, del C.T. "Es trabajo en régimen de subcontratación, aquél realizado en virtud de un contrato de trabajo por un trabajador para un empleador, denominado contratista o subcontratista, cuando éste, en razón de un acuerdo contractual, se encarga de ejecutar obras o servicios, por su cuenta y riesgo y con trabajadores bajo su dependencia, para una tercera persona natural o jurídica dueña de la obra, empresa o faena, denominada la empresa principal, en la que se desarrollan los servicios o ejecutan las obras.
}

Sin embargo, la ley excluyó expresamente las obras o los servicios que se ejecutan o prestan de manera discontinua o esporádica: "Con todo, no quedarán sujetos a las normas de este Párrafo las obras o los servicios que se ejecutan o prestan de manera discontinua o esporádica" (Art. 183-A, inc. $1^{\circ}$, última parte, del CT). 
tación y, del otro, las partes de esta institución; además incorpora un elemento discutible: supuesta exigencia del lugar en donde se realiza la obra o servicio. Conjuntamente, la ley excluyó expresamente las obras o los servicios que se ejecutan o prestan de manera discontinua o esporádica ${ }^{15}$.

El objeto de la subcontratación es 'el acuerdo contractual por el cual se encarga al contratista o subcontratista, en su caso, de ejecutar obras o servicios, por su cuenta y riesgo y con trabajadores bajo su dependencia, para (...) la empresa principal...'. Del objeto de la subcontratación emana el elemento que es de la esencia de esta institución; el acuerdo contractual por el que el cual la empresa principal encarga a la contratista la ejecución bajo su 'cuenta y riesgo' de la obra o servicio.

Es este elemento el que otorgará identidad a la subcontratación laboral y la separará de otras figuras, como es la cesión ilegal de trabajadores. La doctrina chilena ya ha señalado que el actuar por la cuenta y riesgo significa ${ }^{16}$ : "i. estar dotada de medios materiales y personales necesarios para el desarrollo de la actividad, ii. Asumir las responsabilidades y los riesgos propios del desarrollo de la gestión empresarial, vale decir, actuar por su cuenta y riesgo, iii. desarrollar una actividad propia y específica, esto es, se debe encargar de la ejecución de obras o servicios, y iv. organizar, dirigir y controlar efectivamente el desarrollo de su propia actividad, ejerciendo las funciones inherentes a su condición de empleador".

Respecto a la identificación de las partes, si bien la definición reconoce a las entidades tradicionales que concurren en la subcontratación -lo que no podía ser de otra manera, pues lo contrario habría derivado a una figura distinta-. De una parte, la relación civil o comercial involucra a la empresa mandante y a la empresa contratista. A tal efecto, la ley pasa a denominar como 'empresa principal' al dueño de la obra, la que, a su vez, es persona natural o jurídica, que encarga a otra el objeto de la subcontratación. Ciertamente que, para el análisis respectivo, el contratista pasa a tener la calidad de 'empresa principal' en el supuesto que encarga parte del objeto de la subcontratación. De otra parte, esta la relación laboral, del respectivo empresario contratista o subcontratista, en su caso, con sus respectivos trabajadores.

En cuanto al lugar en que se debe realizar las prestaciones de servicios, ha sido controvertida el alcance de esta exigencia en la configuración de la subcontratación laboral, en cuanto se establecería como requisito que “...los servicios o

\footnotetext{
${ }^{15}$ Como establece la parte final del art. 182 Letra A, inc. $1^{\circ}$ del CT. "Con todo, no quedarán sujetos a las normas de este Párrafo las obras o los servicios que se ejecutan o prestan de manera discontinua o esporádica".

${ }^{16}$ Lizama P., L.; Ugarte C., J. L., Subcontratación y Suministro de Trabajadores, Ed. LexisNexis, Santiago 2007, pp. 19-20.
} 
ejecutan las obras contratadas..." se desarrollen en la empresa principal. De una parte, se ha sostenido que el componente locativo es una exigencia incorporada por la ley, en cuanto lo establece como "elemento tipificante del trabajo en régimen de subcontratación y, por consiguiente, como criterio de imputación de las responsabilidades conexas a dicho régimen"1 ${ }^{\prime 1}$. De otra parte, mayoritariamente se ha rechazado este alcance por la doctrina científica, en cuanto lo relevante de este elemento es "que la empresa principal posea el control o dirección de las labores ejecutadas por el contratista o subcontratista." ${ }^{18}$

\section{c) Efecto de la imputación de la relación laboral a la empresa principal en el supuesto de que se encubra una cesión ilegal de trabajadores}

El nuevo texto legal incorpora el efecto de la imputación de la relación laboral a la empresa principal si los trabajadores prestan servicios sin que se cumplan las exigencias del 'trabajo en régimen de subcontratación', señaladas por la definición, o si la empresa contratista opera como mero intermediario. Además, en tal caso, se configura la infracción a que se refiere el art. 478 del CT., actual 507 del CT., relativa a la simulación de contratación de trabajadores a través de terceros ${ }^{19}$. Por consiguiente, son dos los supuestos que provocan ambos efectos: de una parte, que en un supuesto de subcontratación, los trabajadores la prestación de servicios sin que cumplan las exigencias del trabajo en régimen de subcontratación, o si la empresa contratista opera como mero intermediario ${ }^{20}$.

Pues bien, es este segundo supuesto el que, con exactitud define la cesión ilegal de trabajadores, toda vez que el supuesto contratista no asume bajo su

17 Palavecino, C., Subcontratación. Régimen Jurídico del Trabajo Subcontratado y del Suministro de Personal, Editorial Jurídica de Chile, Santiago 2006, p. 36.

${ }^{18}$ En este sentido, Albornoz S., M. y otros, Subcontratación Laboral y Servicios Transitorios, Ed. LexisNexis, Santiago de Chile, 2007, p. 35. Asimismo, Lizama; Ugarte, cit. nota n. 16, pp. 21 y ss.

${ }^{19}$ Art 183-A, inciso final, del CT: "Si los servicios prestados se realizan sin sujeción a los requisitos señalados en el inciso anterior o se limitan sólo a la intermediación de trabajadores a una faena, se entenderá que el empleador es el dueño de la obra, empresa o faena, sin perjuicio de las sanciones que correspondan por aplicación del artículo 478".

${ }^{20}$ Cierto es que la figura de la imputación de la relación a la empresa principal estuvo mejor definida en el Proyecto de Ley original que establecía: "No es trabajo en régimen de subcontratación aquel que realice el trabajador personalmente en condiciones de subordinación o dependencia respecto del dueño de la obra, empresa o faena o aquel en que el trabajador es puesto a disposición de ésta por un intermediario, sin ajustarse a las normas del párrafo siguiente. En ambos casos se entenderá que el empleador es el dueño de la obra, empresa o faena" (véase, "Historia de la Ley № 20.123", Impresión de Biblioteca de Congreso Nacional, Chile, 2006, p. 25).

Sin embargo, dicho concepto fue suprimido en el Primer Informe de la comisión del Trabajo del Senado y sólo fue reincorporada en términos similares a su redacción final por la Comisión Revisora Historia de la Ley No 20.123 ("Historia de la Ley 20.123", cit. nota n. 20, p. 495). 
cuenta y riesgo la ejecución de obra o servicio, sino que la dirección de la misma la mantiene la empresa principal, la que consiguientemente, dirige la prestación de servicios de los trabajadores contratados para tal efecto.

\section{d) Establecimiento de un régimen de responsabilidad:} solidaria o subsidiaria

La nueva regulación establece un régimen de responsabilidad de la empresa que encarga la obra, o del contratista en su caso, respecto de las obligaciones laborales y previsionales de dar -incluidas las indemnizaciones legales que correspondan por término de contrato de trabajo- de las empresas contratistas y subcontratistas, la que será solidaria o subsidiaria en atención a las medidas adoptadas en conformidad a la ley.

Por las obligaciones antes señaladas, la ley establece una responsabilidad solidaria para la empresa principal, o contratista, en su caso $^{21}$. Por tal motivo "el trabajador, al entablar la demanda en contra de su empleador directo, podrá hacerlo en contra de todos aquellos que puedan responder de sus derechos..." (art. 183 B, inc. 4º del CT). Pero la responsabilidad también puede ser subsidiaria y lo será cuando la empresa principal hubiere hecho efectivo el derecho a ser informado y el derecho a retención a que se refiere la ley. En tal supuesto, el trabajador deberá accionar contra el principal obligado y sólo en el supuesto de insuficiencia de bienes podrá accionar frente a la empresa principal.

e) Establecimiento de una obligación directa de la empresa principal: el deber de protección en el trabajo, en lo relativo a la seguridad laboral

Conjuntamente, la ley ha establecido la obligación directa de la empresa principal, o contratista en su caso, en lo relativo a la protección general en el trabajo de quienes laboran en su obra, empresa o faena, cualquiera sea su dependencia; ello en conformidad a la norma general de seguridad laboral, es decir el Art. 184 del C.T. y a las normas de desarrollo ${ }^{22}$.

\footnotetext{
${ }^{21}$ El proyecto sólo establecía una responsabilidad subsidiaria, sin embargo se cambió a responsabilidad solidaria. Tal cambio se produce en el Segundo Trámite Constitucional, en donde por indicaciones presentadas por los señores diputados en la Comisión de Trabajo se cambia de subsidiariedad a solidaridad ("Historia de la Ley 20.123", cit. p. 456).

${ }^{22}$ Éstas son el Art. 66 bis de la Ley $N^{\circ} 16.744$ (sobre el Seguro Social ante accidentes del trabajo y enfermedades profesionales), incorporado por la Ley $N^{\circ} 20.123$, y en el D.S. 594, de 1999, del Ministerio de Salud. Además, se ha dictado el D.S. 776 (de 18 de enero de 2007), del Min. del Trabajo, que contiene el Reglamento para la aplicación del Art. 66 bis de la Ley N²0.123.
} 
f) Las carencias de la ley: no establecimiento de instrumentos jurídicos frente a nuevos riesgos de la subcontratación

Sin perjuicio de la regulación que amplía las exigencias para la subcontratación, la ley no da respuesta a varios de los nuevos riesgos de la subcontratación laboral, es decir, de una parte, la diversidad de estatutos jurídicos al interior de una misma unidad productiva respecto de trabajadores que realizan incluso las mismas actividades $y$, de la otra, las dificultades que se presentan para el desarrollo de la actividad sindical. Cabe señalar que el sistema de relaciones laborales chileno ha presentado diversas manifestaciones respecto del primer riesgo de la subcontratación laboral, particularmente, el relativo a la demanda de igualdad salarial23.

\section{El suministro de trabajo}

\section{a) Antecedentes}

A través del suministro de trabajadores un trabajador se obliga con su empleador a prestar servicios para un tercero, por un período transitorio, en las condiciones y por el tiempo que éste le señale. Por consiguiente, este peculiar contrato de trabajo tiene tres partes: una corresponde al trabajador y las otras dos tienen atribuciones correspondientes al empleador.

Con anterioridad a la vigencia de la Ley $N^{\circ} 20.123$, este supuesto de descentralización productiva no estaba admitido en el ordenamiento jurídico laboral chileno, toda vez que la única relación laboral que reconocía es la que se establece entre un trabajador y un solo empleador ${ }^{24}$. Así lo había reconocido, por lo demás, la Dirección del Trabajo, quien había señalado que "no existe norma de derecho laboral que pudiere apoyar a legitimar una eventual legalidad del vínculo entre trabajadores y determinados agentes o representantes de empresas colocadoras" ${ }^{\prime 25}$. No obstante, sobre esta materia la jurisprudencia judicial fue contradictoria ${ }^{26}$.

\footnotetext{
${ }^{23}$ En tal sentido véase dos posiciones sobre la materia. De una parte, THAYER A., W., "Opinión tentativa para el caso de trabajadores de contratistas en las grandes empresas del Cobre", Revista Laboral Chilena № 163, enero de 2008, pp. 69-72. De otra parte, a López F., D., "Subcontratación laboral e igualdad salarial", Revista Laboral Chilena № 166, mayo, 2008, pp. 66 a 69.

${ }^{24}$ Tal como se establece normativamente en el artículo $7^{\circ}$ del CT.

${ }^{25}$ Dictamen de la Dirección del Trabajo № 5487/259, de 22 de septiembre de 1992; en BODT № 45, de octubre de 1992, pp. 41 y ss.

${ }^{26}$ Vid. Infra, Sección 3.2.b, respecto de los "Antecedentes jurisprudenciales sobre la configuración de la infracción laboral".
} 


\section{b) El régimen jurídico del suministro de trabajo}

Fue la Ley $\mathrm{N}^{\circ} 20.123$, de $2006^{27}$, la que estableció la procedencia del suministro de trabajo en nuestro ordenamiento jurídico, pero sujetándola a especificas exigencias; otro análisis es si estas exigencias son suficientes para proteger efectivamente los derechos de los trabajadores.

Las exigencias que se establecieron son las siguientes: En primer lugar, el suministro de trabajo sólo procede por parte de empresas denominadas de servicios transitorios, que cumpliendo los requisitos legales estén, además, autorizadas a tal efecto. En segundo término, el contrato que se celebra entre la empresa de servicios transitorios y la empresa receptora de la prestación de servicios -esta es la empresa usuaria-, sólo procede por determinadas causas y además está sujeto a específicas solemnidades. En tercer lugar, el contrato de trabajo plantea las especificidades de una relación laboral triangular, por lo que la ley señala los específicos derechos y obligaciones de cada una de las tres partes.

\section{c) La empresa de servicios transitorios}

Esta es, en conformidad a ley, la persona jurídica, inscrita en el registro respectivo, que tenga por objeto social exclusivo poner a disposición de terceros denominados para estos efectos empresas usuarias, trabajadores para cumplir en estas últimas, tareas de carácter transitorio u ocasional, como asimismo la selección, capacitación y formación de trabajadores, así como otras actividades afines en el ámbito de los recursos humanos. La empresa de servicios transitorios debe constituirse expresamente para ese fin y la ley la sujeta, además de otras exigencias, a la garantía que debe prestar a fin de caucionar el cumplimiento de las obligaciones laborales.

\section{d) El contrato de puesta a disposición}

Este es el contrato que se celebra entre la empresa de servicios transitorios y la empresa usuaria, a través de la cual la primera pone a disposición de trabajadores a la segunda. Dicho contrato debe constar por escrito y debe indicar la causal invocada para la contratación de servicios transitorios, los puestos de trabajo para los cuales se realiza, la duración de la misma y el precio convenido.

En tal sentido, la ley establece las causas por las cuales procede el contrato de puesta a disposición $-y$ todas ellas tienen como fundamento el tratarse de

\footnotetext{
${ }^{27}$ La Ley $N^{\circ} 20.123$ fue publicada en el Diario Oficial el 16 de octubre de 2006 y entró en vigencia el 14 de enero del 2007. La Ley № 20.123 introdujo un nuevo Título VII al Libro Primero del Código del Trabajo, el que distingue entre un Párrafo $1^{\circ}$ "Del trabajo en régimen de subcontratación" y un Párrafo $2^{\circ}$ "De las empresas de servicios transitorios, del contrato de puesta a disposición de trabajadores y del contrato de trabajo de servicios transitorios".
} 
labores esencialmente temporales ${ }^{28}-$, como también específicas causas de improcedencia del contrato de puesta a disposición de trabajador ${ }^{29}$.

\section{e) El contrato de trabajo de servicios transitorios}

Este contrato de trabajo plantea una particularidad, si bien hay un solo trabajador se plantean dos sujetos como empleadores: la empresa de servicios transitorios, EST, y la empresa usuaria. Así, la obligación del trabajador es prestar servicios a la empresa usuaria, pero es la empresa de servicios transitorios la que mantiene la obligación de pagar la remuneración determinada por el tiempo servido. En todo caso, la facultad de organizar y dirigir la actividad laboral la tiene la empresa usuaria.

La empresa usuaria es, a su vez, responsable subsidiariamente de las obligaciones que correspondan a la empresa suministradora, salvo en las obligaciones de higiene y seguridad en el trabajo, respecto de las cuales es responsable directa.

\section{f) Las carencias de la ley: no establecimiento de instrumentos jurídicos frente a los riesgos de la subcontratación}

Si bien la ley laboral admite el suministro de trabajo estableciendo las específicas exigencias, no estableció las garantías para el ejercicio de los derechos colectivos de trabajo de los trabajadores contratados por las empresas de servicios transitorios, como sí lo han hecho otros ordenamientos jurídicos ${ }^{30}$.

\section{LA CESIÓN ILEGAL DE TRABAJADORES}

\section{Configuración de la cesión ilegal de trabajadores}

Como se ha señalado, la cesión ilegal de trabajadores se configura en los supuestos de externalización laboral sin que se cumplan las exigencias legales;

\footnotetext{
${ }^{28}$ Como es entre otras causas (artículo 183-Ñ) , la suspensión del contrato de trabajo o de la obligación de prestar servicios, según corresponda, de uno o más trabajadores por licencias médicas, descansos de maternidad o feriados.

${ }^{29}$ Estos casos, en conformidad al Art. 183-P son los siguientes:

“a) para realizar tareas en las cuales se tenga la facultad de representar a la usuaria, tales como los gerentes, subgerentes, agentes o apoderados;

b) para reemplazar a trabajadores que han declarado la huelga legal en el respectivo proceso de negociación colectiva; o

c) para ceder trabajadores a otras empresas de servicios transitorios."

${ }^{30}$ Particularmente importante es, en esta materia, el Convenio 181 de 1997, el que se refiere a las empresas suministradoras de trabajadores en tres órdenes de materia: la responsabilidad y garantía de éstas ante sus obligaciones con los trabajadores, su improcedencia en las áreas económicas que se definan y las garantías a establecer para el efectivo ejercicio de los trabajadores de sus derechos sindicales.
} 
configurándose de esta manera en el supuesto de que la externalización no sea admitida, que no cumpla las específicas exigencias de la externalización laboral $\mathrm{o}$, finalmente, en el supuesto de encubrimiento de interposición de mano de obra. Estas tres formas se han presentado en nuestro ordenamiento jurídico, aunque no conjuntamente.

\section{Los antecedentes jurídicos de la cesión ilegal de trabajadores}

\section{a) Referencias normativas}

El ordenamiento jurídico chileno regula por primera vez la cesión ilegal de trabajadores, al incorporar una infracción laboral especial, a través de la Ley № 19.250, de noviembre de 1993, referida a la simulación de contratación de trabajadores a través de terceros. En efecto, es a través de la Primera Reforma Laboral $^{31}$, que por primera vez se tipifica como infracción la simulación de trabajadores a través de terceros, aunque la disposición exigió que esta simulación fuera dolosa ${ }^{32}$. Además de constituir una infracción, el empleador principal queda obligado a todas las prestaciones laborales que correspondiere a sus trabajadores ${ }^{33}$.

A través de la Ley $N^{\circ} 19.759$, de octubre de 2001, que constituye a este efecto la Segunda Reforma Laboral, se modifica tanto la tipificación de la infracción laboral, como los efectos de la misma. En efecto (1) se quita la exigencia del obrar doloso, toda vez que se configura con que se "...simule la contratación de trabajadores a través de terceros,...". (2) Se aumenta la multa a un monto que va de 5 a 100 UTM. (3) Se establece una responsabilidad solidaria entre el empleador y los terceros por los derechos laborales y previsionales que correspondan al trabajador. (4) Se mantiene la responsabilidad del empleador al pago de todas las prestaciones laborales que correspondieren al trabajador. Además, el legislador define la acción que debe interponer el trabajador: demanda en juicio ordinario. (5) Se establece un plazo de prescripción de los derechos y acciones cinco años contados desde que las obligaciones se hicieron exigibles ${ }^{34}$, plazo que es bastante superior al ordinario que sólo es de dos años.

\footnotetext{
${ }^{31}$ Las Reformas Laborales son las modificaciones efectuadas al Plan Laboral, que constituye el modelo normativo impuesto por el régimen militar. Las modificaciones efectuadas a través de las Reformas Laborales han sido hechas en el nuevo sistema democrático. Y hasta la fecha hay dos procesos de reformas: la primera, que va de 1990 a 1993 y la segunda, que es del año 2001.

${ }^{32}$ Así se incorpora al Código del Trabajo, el siguiente Art. 478, inciso primero:

"Artículo 478.- Se sancionará con una multa a beneficio fiscal de una a doce unidades tributarias mensuales al empleador que dolosamente, simule la contratación de trabajadores a través de terceros,,..$"$

${ }^{33}$ Art. 478, inc. final, del CT.

${ }^{34}$ Artículo único, № 100 de la Ley No 19.759, de 5 de octubre de 2001.
} 
Cabe señalar que en todo este período de vigencia de la infracción laboral relativa a la "simulación de trabajadores a través de terceros", la cesión de trabajo era improcedente de acuerdo a derecho; por lo que la infracción era aplicable tanto al supuesto general de suministro de trabajo como a la subcontratación, en el supuesto de que el objeto sea precisamente el suministro de mano de obra.

b) Antecedentes jurisprudenciales sobre la configuración de la infracción laboral

Respecto a la configuración de la infracción, y aunque los estudios empíricos mostraban de casos de suministro de trabajo a través de empresas suministradoras ${ }^{35}$, la jurisprudencia era contradictoria al pronunciarse sobre dicha infracción, en cuanto resolvió que no se configuraría dicha infracción en virtud del derecho de libertad de empresa ${ }^{36}$.

c) Antecedentes jurisprudenciales sobre los efectos jurídicos de la cesión ilegal de trabajadores

La jurisprudencia tuvo oportunidad de pronunciarse sobre tales efectos jurídicos, con ocasión del conocimiento de seudas subcontrataciones laborales, de una parte, y del suministro al interior de grupos de empresas, de la otra.

c.1. En los supuestos de seudas subcontrataciones laborales, aplicó la norma de responsabilidad subsidiaria que entonces regía en virtud del entonces vigente artículo 64 del C.T., aunque dicha aplicación planteó algunas particularidades.

En un momento, si bien se reconoce como subcontratación el suministro de trabajo por parte de la empresa contratista a la empresa principal ${ }^{37}$, por consiguiente esta última es subsidiariamente responsable, tal como lo declara la

\footnotetext{
${ }^{35}$ En tal sentido, véase la información otorgada por la Encuesta Laboral, Encla, de la Dirección del Trabajo, de 1998, de 1999, 2002 y 2006, cit. nota n. 6 .

${ }^{36}$ En este sentido, Sentencia de la Iltma. Corte de Apelaciones de Santiago, pronunciado en Recurso de Protección en causa Rol 8725/2003, de 30 de marzo del 2004, ejemplar fotocopiado; en cuanto el Considerando $15^{\circ}$ expone: "Que el derecho a desarrollar la actividad económica importa la facultad de su titular para elegir y definir, del modo más conveniente a su interés, la forma de ejecutar su giro empresarial, libertad que en el presente caso se ve menoscabada al impedírsele-en el hecho-al recurrente contratar con proveedores o externalizar la prestación de sus servicios, pues no otro efecto se produce al sancionarlo con una infracción por simular la contratación de trabajadores, si antes la autoridad fiscalizadora del trabajo ha reconocido que la recurrente posee una estructura propia y separada de las empresas prestadoras de servicios y que no se observa una relación de propiedad entre ellas".

${ }^{37}$ Como establece la Sentencia del Sexto Juzgado Laboral de Santiago, de 25 de octubre de 2003, Rol 460 de 2002 (en ejemplar fotocopiado en Biblioteca de la CS.) en su Considerado $6^{\circ}$, respecto de la prueba rendida: "... b) que, sus funciones las cumplían en dependencias de la 'C.x de Chile S.A.', realizando el trabajo para ella..." "...d) que 'Y Chile Ltda.' era contratista de la 'C.X de Chile S.A.' proporcionándole la primera mano de obra la segunda".
} 
sentencia de instancia, la Corte Suprema revoca dicha consideración, en atención a que la obligación no estaba comprendida en el art. 64 del C.T. En efecto, entonces se discutía si la indemnización por término de contrato era parte de la responsabilidad subsidiaria establecida por la ley a la empresa principal ${ }^{38}$.

Con posterioridad, y aplicando la misma normativa, en un caso similar, la C.S. resuelve que la empresa principal debe responder por todas las prestaciones demandadas como responsable subsidiaria, toda vez que "...la unidad entre las empresas demandadas como dueña de la obra y contratista respectivamente, es de una entidad mayor a la que contemplan las normas que se denunciaron como infringidas." ${ }^{\prime \prime 9}$

Por consiguiente, es esta relación mayor a la subcontratación la que plantea la incorporación de tal responsabilidad por dicha obligación ${ }^{40}$. Y este vínculo no es otro que la cesión o suministro ilegal de trabajo, aunque el fallo omite tal expresión. En efecto la empresa contratista se había constituido con el único fin de prestarle servicios a la empresa principal y, además, esta última "...determinaba el personal que la contratista podía contratar para realizar las tareas encomendadas, es decir, en definitiva, nadie podía ser contratado sin que ésta prestara su aprobación." 41

c.2. Distinta debió ser la respuesta en el caso de suministro de trabajo al interior de los grupos de una empresa. En efecto, alrededor del año 2000, la jurisprudencia chilena atribuye responsabilidad conjunta a las empresas que integran un grupo de laboral de empresas, exigiendo para su configuración como tal que las empresas tengan una dirección unitaria ${ }^{42}$. En el supuesto que se trata, dentro de un grupo de empresas, o "Holding" como eran denominados por esos años por parte de los Tribunales de Justicia, una empresa suministra trabajadores a la otra, en circunstancias que ambas "conforman un todo, que funcionan en un mismo domicilio y que son dirigidas por los mismos ejecutivos." ${ }^{\prime 4}$ Por lo que concluye: "... conforme a lo anterior más que responsabilidad subsidiaria, existe entre las demandadas 'Administradora de servicios X S.A.' y "Supermercados Y

\footnotetext{
${ }^{38}$ Sentencia de la Excma. Corte Suprema, pronunciada en Recurso de Casación Rol 2.055 de 2005, 31 de agosto de 2006, ejemplar fotocopiado en Biblioteca de CS.

${ }^{39}$ Sentencia de la Excma. Corte Suprema, Rol 695 de 2007, 20 de diciembre de 2007, Considerando $14^{\circ}$, ejemplar fotocopiado en Biblioteca de CS.

${ }^{40}$ En igual sentido, Sentencia de la Excma. Corte Suprema, Rol 4611 de 2007, 17 de enero de 2008, ejemplar fotocopiado en Biblioteca de CS.

${ }^{41}$ Sentencia de la Excma. Corte Suprema, Rol 695 de 2007, 20 de diciembre de 2007, Considerando $12^{\circ}$, ejemplar fotocopiado en Biblioteca de CS.

${ }^{42}$ Rojas M., I.; Aylwin Ch., A., Los Grupos de Empresas en el Derecho Chileno del Trabajo, Ed. LexisNexis, Santiago, 2007.

${ }^{43}$ Sentencia del Noveno Juzgado laboral de Santiago, de 15 de octubre de 2002. Rol 3.316 de 2001 (en fotocopia de Biblioteca de CS.), Considerando $15^{\circ}$.
} 
S.A." responsabilidad conjunta respecto de todos y cada una de las prestaciones reclamadas en autos, no existiendo entre las mismas los supuestos establecidos en el artículo 64 del Código del Trabajo." ${ }^{44}$. Sin embargo, la apelación de dicha sentencia, como el fallo en recurso de casación ${ }^{45}$, sólo admitieron una responsabilidad subsidiaria, toda vez que la responsabilidad conjunta no había sido planteada en la demanda.

3. Actual régimen jurídico de la cesión ilegal de trabajadores

a) El actual régimen jurídico

Finalmente, la Ley № 20.123, de 2006, admite el suministro de trabajadores a través de empresas externas, estableciendo el específico régimen jurídico para su procedencia. A la vez, mantiene la infracción de simulación de trabajadores a través de terceros, aunque con una modificación, agrega el importante efecto de la contratación de trabajadores a través de terceros: se entenderá que es empleador el dueño de la obra o faena.

\section{b) La configuración de los diversos tipos de cesión ilegal de trabajadores}

La cesión ilegal se configura por incumplimiento de los requisitos esenciales de la subcontratación y del suministro de trabajo.

b.1. En efecto, el primer tipo de cesión ilegal se refiere a la simulación de subcontratación laboral - o seudo subcontratación- en cuanto los servicios prestados no cumplen los requisitos del "trabajo en régimen de subcontratación" -señalados por el art. 183 A del C.T.- o sólo se limitan a la intermediación de trabajadores a una faena.

Dado el tenor literal del precepto, este tipo laboral comprendería dos supuestos: En primer lugar, que no cumpla con las exigencias establecidas por el legislador para configurar "el trabajo en régimen de subcontratación". En segundo término, la limitación la intermediación de trabajadores a una faena. Sin embargo, ambos supuestos se refieren al mismo objeto: la simulación como subcontratación de suministro de trabajo. En efecto, en el primer supuesto, las exigencias establecidas deben estar referidas al contenido de la convención sobre subcontratación, y esta es que respecto de la empresa principal, el contratista "...se encarga de ejecutar obras o servicios, por su cuenta y riesgo y con trabajadores bajo su dependencia,...". Si no existiera dicho elemento, lo que se produciría es un suministro de trabajo, lo mismo que en el segundo supuesto.

\footnotetext{
${ }^{44}$ Sentencia del Noveno Juzgado laboral de Santiago, cit. nota n. 44, Considerando $16^{\circ}$.

${ }^{45}$ Sentencia de la Iltma. Corte de Apelaciones de Santiago, Rol 6198 de 2002, 16 de septiembre de 2003; y Sentencia de la Excma. Corte Suprema, Rol 4675 de 2003, 25 de marzo de 2004.
} 
El segundo tipo se refiere al suministro de trabajo admitido por ley, que no cumple las exigencias definidas de máxima relevancia por la misma ley, sin las cuales no se configura el contrato de trabajo de servicios transitorios.

Son cuatro los supuestos establecidos por la ley: (1) Que el contrato de puesta a disposición de trabajadores sea para realizar las actividades expresamente prohibidas, caso en el cual la usuaria incurre en una infracción especial (Art. 183-P, del CT). (2) Que el contrato de trabajo celebrado sea para el desarrollo de actividades distintas a las que justifican de servicios transitorios (Art. 183-U, del CT). (3) Que el contrato celebrado encubre una relación de trabajo permanente con la empresa usuaria (Art. 183-U, del CT). (4) Que la empresa usuaria contrate a un trabajador de servicios transitorios por intermedio de empresas no inscritas en el registro que lleva a tales efectos la Dirección del Trabajo (Art. 183-AA, del CT).

\section{c) Los efectos jurídicos de la cesión ilegal de trabajadores}

Son dos los efectos que establece la ley respecto de la cesión ilegal de trabajadores: en primer lugar, la imputación de la relación laboral a la empresa principal o usuaria, según corresponda y, en segundo término, se configura la infracción referida a la simulación de contratación de trabajadores a través de terceros.

\section{c.1. Imputación de la relación laboral a la empresa principal o usuaria}

El nuevo texto legal incorpora el efecto de la imputación de la relación laboral a la empresa principal o usuaria en el caso que se configuren los tipos laborales indicados.

En primer lugar, respecto del primer tipo laboral, operaría esta imputación de la relación laboral a la empresa principal en el supuesto que no se cumplan las exigencias del trabajo en régimen de subcontratación -el contratista no se encarga bajo su cuenta y riesgo de la obra o faena contratado por lo que los trabajadores tampoco dependen de él sino que de la empresa principal- , o en el caso que la empresa contratista opera como mero intermediario. En tal caso, y como establece la ley laboral, "...se entenderá que el empleador es el dueño de la obra, empresa o faena,..."

\footnotetext{
${ }^{46}$ Cierto es que la figura de la imputación de la relación a la empresa principal estuvo mejor definida en el Proyecto de Ley original que establecía: "No es trabajo en régimen de subcontratación aquel que realice el trabajador personalmente en condiciones de subordinación o dependencia respecto del dueño de la obra, empresa o faena o aquel en que el trabajador es puesto a disposición de ésta por un intermediario, sin ajustarse a las normas del párrafo siguiente. En ambos casos se entenderá que el empleador es el dueño de la obra, empresa o faena (en ("Historia de la Ley 20.123", cit. nota n. 20, p. 25).

Sin embargo, dicho concepto fue suprimido en el Primer Informe de la Comisión del Trabajo del Senado y sólo fue reincorporada en términos similares a su redacción final por la respectiva Comisión Revisora en ("Historia de la Ley 20.123", cit. nota n. 20, p. 495).
} 
En segundo término, respecto del tipo laboral referido al incumplimiento de las exigencias del suministro de trabajo, en los cuatro supuestos se establece que el trabajador se considerará como dependiente de la empresa usuaria, por lo que el contrato de trabajo se regula por las normas generales, excluyéndose la aplicación de las normas del Párrafo que regula el suministro de trabajo ${ }^{47}$.

\section{c.2. Configuración de la infracción referida a la simulación de contratación de trabajadores a través de terceros, Art. 507 del CT}

Este precepto, corresponde al anterior art 478, al que fueron incorporadas algunas modificaciones ${ }^{48}$ : Al efecto, será el empleador real quien quedará sujeto al cumplimiento de todas las obligaciones laborales y previsionales y al pago de todas las prestaciones que correspondieren respecto de los trabajadores objeto de la simulación.

\section{LA ESCASA EFICACIA DE LAS NORMAS QUE CONFIGURAN LA CESIÓN ILEGAL DE TRABAJADORES}

\section{Antecedente}

Si bien la Ley № 20.123 constituyó un avance en el objetivo de regulación de la externalización laboral y en la definición y tutela de específicos derechos laborales, no es menos cierto que las normas relativas a cesión ilegal de trabajadores han tenido escasa eficacia, considerando, en especial, la masificación de esta manifestación en las relaciones laborales en Chile.

El punto de partida, en este análisis, es la constatación de una alta externalización de las relaciones laborales por parte de las empresas, toda vez que formalmente se subcontratan actividade ${ }^{49} \mathrm{O}$ contratan suministro de trabajadores $^{50}$. Ello no presentaría cuestionamiento en una perspectiva jurídico formal, en cuanto son formas lícitas de externalización. El problema se plantea al detectar

\footnotetext{
${ }^{47}$ Párrafo $2^{\circ}$ del Titulo VII del Libro I del CT.

${ }^{48}$ Art 183-A, inciso final, del CT: "Si los servicios prestados se realizan sin sujeción a los requisitos señalados en el inciso anterior o se limitan sólo a la intermediación de trabajadores a una faena, se entenderá que el empleador es el dueño de la obra, empresa o faena, sin perjuicio de las sanciones que correspondan por aplicación del artículo 478."

${ }^{49}$ Vid. Supra, Sección 2.2. La Magnitud de la externalización laboral en Chile; en cuanto como se señaló, el $41,2 \%$ de las empresas subcontrata actividades a terceros (Encla 2006, cit. nota n. 6, pp. 31 y ss.).

${ }^{50} \mathrm{Si}$ bien las cifras sobre suministro son relativamente bajas, toda vez que de acuerdo con la Encla 2006 no superaba el 5,1\% de la mano de obra al interior de las empresas, dicha información fue recabada a la fecha en que el suministro de trabajo era ilegal. Por consiguiente, una vez admitida esta forma de externalización por parte del ordenamiento jurídico laboral, habría que revisar cuál es la incidencia que tiene en el ámbito de las relaciones económicas y laborales.
} 
supuestos encubrimientos de cesiones ilegales de trabajadores, que afectarían particularmente a la subcontratación laboral.

\section{La posible masificación de la cesión ilegal de trabajadores}

La afirmación de esta supuesta masificación de cesión ilegal se plantea en base a dos antecedentes: En primer lugar, los datos empíricos plantean niveles y particularidades de la subcontratación que hacen presumir la concurrencia de cesión ilegal. En segundo término, la actividad fiscalizadora de la Dirección del Trabajo verifica una alta incidencia de esta forma ilegal de externalización laboral.

a. Las presunciones en base a la información empírica. Las peculiaridades que plantea la subcontratación laboral en Chile, de acuerdo a lo informado por la Encuesta Laboral, Encla de la Dirección del Trabajo, en cuanto, como se ha señalado, además de presentarse mayoritariamente en la gran y mediana empresa, una parte importante de la subcontratación es relativa a la actividad principal de la empresa, específicamente un 32,6\%. Es esta subcontratación de la actividad principal la que presenta varias particularidades. En primer lugar, un bajo nivel de formalidad en la contratación entre las empresas involucradas -principal y subcontratista-, toda vez, el contrato sólo es de palabra (un 9,3\% de los contratos) o de palabra con entrega de boleta o factura (un $51,8 \%$ de los contratos), mientras que sólo un 26,1 de los contratos es escriturado. En segundo término, las empresas subcontratistas constituyen en una importante proporción -en $43,1 \%$ de los casos-, grupos familiares, talleres o empresas muy pequeñas, que son, como es sabido, 'un sector de conocida debilidad económica'. ${ }^{51}$ En tercer lugar, y de acuerdo a la misma fuente de información -que proviene de los empleadores encuestados-, se presenta un alto nivel de dependencia económica de estas empresas subcontratistas que realizan actividades del giro principal, respecto de la empresa principals2.

Todo lo anterior, "plantea interrogantes sobre la real autonomía económica de una y otra empresa y también respecto de la relación de los trabajadores con su empleador y con el empleador principal"53.

b. Los resultados que arroja la actividad fiscalizadora de la Dirección del Trabajo. A partir de la entrada en vigencia de la Ley No 20.123, la Dirección del Trabajo implementa una política de fiscalización en materia de subcontra-

\footnotetext{
${ }^{51}$ Encla 2006, cit. nota n. 6, p. 35.

${ }^{52}$ En efecto, de acuerdo con la Encla 2006 (Encla 2006, cit. nota n. 6, pp. 36 y ss.) un 29,6\% de los empresas subcontratistas está conformada totalmente o en parte por extrabajadores de la empresa principal, un 45,6\% de las empresas subcontratistas reciben maquinarias, materiales o insumos de la empresa principal y un $31,5 \%$ de las primeras tiene capital de la empresa principal.

${ }^{53}$ Encla 2006, cit. nota n. 6, pp. 36 y ss.
} 
tación, particularmente relevantes son los instrumentos jurídicos que definen el contenido y alcance de la subcontratación y la configuración de la infracción de acuerdo con el Art. 183.A del C.T., es decir, el Dictamen 14/005 de 10 de enero de $2007^{54}$ y la Circular $N^{\circ} 82$ de 26 de septiembre de $2007^{55}$.

Debe recordarse al efecto que la función fiscalizadora de la Dirección del Trabajo se fundamenta en el mandato legal del Art. 1 de su Estatuto Orgánico (D.F.L. 2 de 1967), en cuanto le corresponde particularmente "la fiscalización de la aplicación de la legislación laboral; función que, además, la comparten las respectivas entidades de la administración del trabajo de cada Estado, en cuanto constituye un organismo necesario en la eficacia del Derecho del Trabajo, tal como ha establecido la Organización Internacional del Trabajo en el Convenio 81 de 1947. Al efecto de la fiscalización de las normas sobre subcontratación laboral, la Dirección del Trabajo puso el énfasis en la verificación de la efectiva configuración de la subcontratación laboral y por ende que "... los servicios sean ejecutados por el contratista con trabajadores bajo su dependencia". ${ }^{56} \mathrm{Si}$ no se cumplen dicha exigencia de la esencia de la fiscalización, deben registrase los antecedentes de la infracción, en conformidad al formulario F8-3 (acta de constatación de hechos en fiscalización de la Ley № $20.123 \ldots$..), entre cuyos antecedentes debe anotarse respecto de que sujeto se plantea la manifestación de subordinación o dependencia ${ }^{57}$ del o los trabajadores supuestamente subcontratados ${ }^{58}$.

\footnotetext{
${ }^{54}$ Que Fija sentido y alcance de los artículos 183 -A, 183.-B, 183-C y 183-D del Código del Trabajo, incorporados por la Ley № 20.1234, publicada en el Diario Oficial de 16.10.2006" en Boletín Oficial de la Dirección del Trabajo, febrero de 2007, pp. 105-117.
}

${ }^{55}$ Que "Modifica y complementa procedimiento de fiscalización destinado a verificar cumplimiento de la Ley $\mathrm{N}^{\circ} 20.123$, relativo al trabajo en régimen de subcontratación", en Boletín Oficial de la Dirección del Trabajo, octubre de 2007, pp. 73-83.

${ }^{56}$ Circular 82, de 26 de septiembre de 2007, en Boletín Oficial de la Dirección del Trabajo, octubre de 2007 , pp. 83 y ss.

${ }^{57}$ Debe recordarse el efecto que la subordinación o dependencia además de constituir un elemento de la esencia del contrato de trabajo, lo tipifica como tal. Este elemento se define en una concreta relación por la concurrencia de algunos de las "manifestaciones demostrativas", como señala la jurisprudencia administrativa, o "elementos demostrativos", como los denomina la jurisprudencia judicial. En este sentido, véase de Urzúa M., L., El vínculo de la subordinación o dependencia, como elemento del contrato de trabajo, Ed. LexisNexis, Santiago de Chile, 2004.

${ }^{58}$ El formulario F8-3 estableció las siguientes manifestaciones que deben verificarse en el caso concreto de fiscalización: (1) Imparte instrucciones directa a los trabajadores, quienes se sujetan a ellas. (2) Determina, sea genérica sea específicamente, la forma y oportunidad de ejecutar las labores de los trabajadores. (Organiza y administra la actividad laboral de los trabajadores. (4) Establece la carga de trabajo diaria, semanal, mensual, de los trabajadores. (5) Controla, fiscaliza o supervisa el desarrollo de las labores del trabajador. (6) Ejerce la potestad disciplinaria respecto de los trabajadores. (7) Establece y/o controla el régimen de jornada y sus interrupciones. (8) Determina la contratación y/o despido de los trabajadores. 
Algunos de los resultados de la actividad fiscalizadora fueron conocidos a través de los Recursos de Protección que varias de las empresas que fueron fiscalizadas interpusieron entablaron en contra de la Dirección del Trabajo. En estas acciones judiciales Ilama la atención el alto número de trabajadores supuestamente subcontratados pero que en definitiva dependen de la empresa principal. Sin tener los datos de la incidencia en cada una de las empresas, en los casos concretos conocidos a través de los recursos de protección el número de trabajadores cuyos contratos de trabajo deben ser de definidos en razón del real empleador, bordea los quinientos y en algunos casos un número mayor; cifra que es bastante alta, aunque se trate de empresas mineras ${ }^{59}$.

\section{El rechazo de la doctrina jurisprudencial a la actividad fiscalizadora de la Dirección del Trabajo}

Frente a los recursos de protección interpuestos por las empresas fiscalizadas, los Tribunales Superiores de Justicia han resuelto mayoritariamente que los Inspectores del Trabajo carecen de facultades para calificar jurídicamente el supuesto de hecho, esto es, definir con quién se configura el contrato de trabajo: con el empleador de la empresa principal o de la contratista. De esta manera, se ha quitado toda vinculación a la instrucción de los respectivos fiscalizadores que ordenaban la imputación del contrato de trabajo al real empleador, es decir, la empresa principal.

De esta Manera, los Tribunales Superiores de Justicia han acogido los recursos de protección en contra la Dirección del Trabajo o los específicos fiscalizadores;

\footnotetext{
${ }^{59}$ Entre otras, se presentan las siguientes causas, aunque se debe considerar que todas ellas afectan a empresas mineras:
}

En sentencia de la Iltma. Corte de Apelaciones de Antofagasta, se involucra a 982 trabajadores en causa Rol 949 de 2007, 28 de enero de 2008. En sentencia de la Excma. Corte Suprema, Rol 953 de 2008, 12 de mayo de 2008 (en ejemplar fotocopiado en Biblioteca de Corte Suprema).

En sentencia de la Iltma. Corte de Apelaciones de Valparaíso, se involucra a 502 trabajadores en causa Rol 659 de 2007, 28 de enero de 2008. En sentencia de la Excma. Corte Suprema, en causa Rol 1062 de 2008 , 12 de mayo de 2008 (en ejemplar fotocopiado en Biblioteca de Corte Suprema).

En sentencia de la Iltma. Corte de Apelaciones de Valparaíso, se involucra a 257 trabajadores en causa Rol 660 de 2007, 28 de enero de 2008. En sentencia de la Excma. Corte Suprema, en causa Rol 1063 de 2008, 12 de mayo de 2008 (en ejemplar fotocopiado en Biblioteca de Corte Suprema).

En sentencia de la Iltma. Corte de Apelaciones de Rancagua, en causa Rol 1.197 de 2007 se involucra a 1.347 trabajadores, 8 febrero de 2008. En sentencia de la Excma. Corte Suprema, en causa Rol 1074 de 2008, 12 de mayo de 2008 (en ejemplar fotocopiado en Biblioteca de Corte Suprema).

En sentencia de la lltma. Corte de Apelaciones de Rancagua, en causa Rol 981 de 2008 se involucra a 767 trabajadores, 6 febrero de 2008. En sentencia de la Excma. Corte Suprema, en causa Rol 1075 de 2008, 12 de mayo de 2008 (en ejemplar fotocopiado en Biblioteca de Corte Suprema).

En sentencia de la Iltma. Corte de Apelaciones de Rancagua, en causa Rol 981 de 2008 se involucra a 1.060 trabajadores, 6 febrero de 2008. En sentencia de la Excma. Corte Suprema, en causa Rol 1076 de 2008, 12 de mayo de 2008, (en ejemplar fotocopiado en Biblioteca de Corte Suprema). 
aunque dicha doctrina, plantea algunas excepciones, ya sea por parte de algunas sentencias de mayoría de Cortes de Apelaciones o de votos disidentes en otras. La Corte Suprema por su parte, a través de la Tercera Sala ha sido constante en la doctrina jurisprudencial mayoritaria, pero con el voto disidente planteado permanentemente por el Ministro D. Alfredo Pierry. Y el punto en debate es si la Dirección del Trabajo y, por ende, los respectivos fiscalizadores tienen tal facultad.

De una parte, se objeta tal facultad en base a la dimensión que ésta tiene, la que debería ejercerse, como señaló en su momento la Corte Suprema ${ }^{60}$, " ... sólo cuando dicho Servicio se encuentre frente a situaciones de infracción a las normas laborales, o sea cuando con su actividad de fiscalización se sorprendan ilegalidades claras precisas y determinadas". Con posterioridad, se objeta la facultad fiscalizadora de la Dirección del Trabajo, en cuanto ésta no comprendería la interpretación de los contratos de trabajo, más aún con el efecto que dicha actividad provoca en cuanto "... los priva de los efectos que les son propios, provocando su extinción, al tiempo que dispone que se celebren otros en su reemplazo". ${ }^{61}$

Ambos fundamentos han sido cuestionados desde la doctrina científica, tanto del Derecho del Trabajo como del derecho Administrativo. En efecto, de una parte se ha calificado como pretensión de "isomorfia" la de la Corte Suprema, al exigir que la fiscalización se efectúe sólo "cuando exista una correspondencia inmediata entre la disposición legal y el hecho, como si se tratara de un objeto y su reflejo" ${ }^{62}$ De otra parte, se afirma la juridicidad de las potestades resolutivas de los órganos de la Administración del Estado en el ordenamiento jurídico chileno ${ }^{63}$.

Asimismo, una doctrina jurisprudencial minoritaria al interior de la Tercera Sala de la Corte Suprema sí reconoce tal facultad de la Dirección del trabajo y sus entidades fiscalizadoras ${ }^{64}$, al plantear que "...la autoridad administrativa está facultada para

\footnotetext{
${ }^{60}$ Por todas, Sentencia de la Excma. Corte Suprema, 29 de mayo de 2007, Considerando $4^{\circ}$ (ejemplar fotocopiado en Biblioteca de C.S.)

${ }^{61}$ Por todas, Sentencia de la Excma. Corte Suprema, Rol 1074,12 de mayo de 2009, Considerando $5^{\circ}$ (ejemplar fotocopiado en Biblioteca de C.S.)

${ }^{62}$ Lizama Portales, Luis, "La Corte Suprema y el ejercicio de las facultades de los Inspectores del trabajo en la ley de subcontratación: Una doctrina y dos consecuencias jurídicas posibles", Revista Estudios Laborales $\mathrm{N}^{\circ} 2$ 2, 2008, p. 97.

${ }^{63}$ FerRada Bórquez, Juan Carlos, "El derecho fundamental a un juez predeterminado por la ley y potestades administrativas: notas a propósito del caso de la Inspección del Trabajo", Revista Estudios Laborales $\mathrm{N}^{\circ} 2,2008$, pp. 5-21.

${ }^{64}$ Por todas, véase Sentencia de la Excma. Corte Suprema, Rol 887 de 2008, 12 de mayo de 2007 (ejemplar fotocopiado en Biblioteca de Corte Suprema)
} 
calificar jurídicamente los hechos, siendo esto parte de la actividad administrativa ${ }^{65}$. Y agrega, "Que la calificación jurídica de los hechos ocurre cada vez que en el procedimiento destinado a la elaboración de un acto administrativo, la autoridad administrativa aplica a un hecho una norma que le sirve de fundamento y que justifica su dictación, o un concepto jurídico indeterminado, por lo que privarla de dicha facultad paralizaría a la Administración e impediría el cumplimiento de su función..." ${ }^{\prime \prime 6}$.

\section{Las vías de cumplimiento de las normas laborales. A propósito de la eficacia general de las normas del Derecho el Trabajo}

Ciertamente que el efecto que tiene la aplicación de la doctrina mayoritaria por parte de los tribunales de justicia es dejar con una mínima eficacia la norma laboral que sanciona, es decir, la cesión ilegal de trabajadores, en cuanto la seudo subcontratación no se limitaría a específicos casos sino que se plantea de forma masiva en el actual sistema de relaciones laborales.

Desechada por los tribunales de Justicia la vía de actuación administrativa, quedaría la acción individual del trabajador para reclamar dicha imputación del contrato de trabajo a su real empleador.

Cierto es que al término del contrato podrá alegar tal calidad y demandar por sus derechos y prestaciones laborales al real empleador. En ello estimo que no procederá discusión alguna. El problema es que no se puede mantener esta práctica del sistema de relaciones laborales en el que el trabajador sólo pueda accionar al término de su relación laboral, tal como sucede en gran parte de los $\operatorname{casos}^{67}$.

Pero ciertamente ipodría el trabajador demandar la imitación del contrato de trabajo a su real empleador, con la pretensión de que la relación laboral permanezca vigente? Ilusoria reivindicación debería responderse, pues el sistema jurídico laboral vigente no garantía la indemnidad al trabajador.

\footnotetext{
${ }^{65}$ Sentencia de la Excma. Corte Suprema, cit. nota n. 64, Considerando $2^{\circ}$, el que agrega "... En efecto, es dicha calificación jurídica la que es indispensable para el ejercicio de esa actividad, en particular para la sanción administrativa, por lo que al hacerlo la Inspección del Trabajo no ha vulnerado lo dispuesto en el artículo $19 \mathrm{~N}^{\circ} 3$ inciso $4^{\circ}$ de la Constitución Política de la República actuando como comisión especial, sino que lo ha hecho en el desempeño de una actividad administrativa...".

${ }^{66}$ Sentencia de la Excma. Corte Suprema, cit. nota n. 64, Considerando $3^{\circ}$, que agrega "...Por lo demás, así lo ha entendido la ley cuando; por ejemplo, el artículo $5^{\circ}$ número 3 de la ley $N^{\circ} 17.322$ sobre cobranza judicial de cotizaciones indica que la oposición del ejecutado será admisible cuando exista 'Errada calificación de las funciones desempeñadas por el trabajador', lo que equivale a decir que ella es admisible cuando la Administración ha efectuado un errada calificación jurídica de los hechos..."

${ }^{67}$ TAPIA G., F., "La necesidad de la reforma procesal laboral y previsional. Una constatación empírica", Anuario de Derecho del Trabajo y Seguridad Social No 2, 2001, pp.17-21. De este estudio se puede concluir que más de la mitad de las causas es por terminación del contrato de trabajo, que es el momento en el cual los trabajadores demandan por el cumplimiento de sus derechos.
} 
En efecto, como señala el mismo voto disidente de la Tercera sala de la Corte Suprema, quien fundamenta el actuar de la Dirección del Trabajo en la necesaria eficacia de las normas laborales: "Que lo anterior tiene particular relevancia, por cuanto la Inspección del Trabajo carece de titularidad para imponer denuncias ante los tribunales, por lo que al prohibirle efectuar la calificación jurídica de los hechos por ser una actividad reservada a los tribunales de justicia, se está despojando de contenido a las normas de protección al trabajador, ya que ningún órgano de control, sea jurisdiccional o administrativo, llevará a cabo dicha calificación, y la eventual conducta transgresora de la ley quedará sin sanción, salvo que sea el propio trabajador afectado el que reclame, lo que en muchos casos resulta ilusorio" ${ }^{.68}$

\section{Observaciones finales}

Es cierto que la Ley $\mathrm{N}^{\circ}$ 20.123, referida tanto a la subcontratación laboral como al suministro de trabajo, efectuó un gran avance en la formulación legal de estas manifestaciones de la descentralización productiva, con el objetivo de regular las relaciones laborales y proteger los derechos de los trabajadores; sin perjuicio de las carencias que se observan, en particular, las faltas de garantías de los derechos colectivos de los trabajadores.

Sin embargo un problema grave que se plantea es el de la eficacia de gran parte de estas normas, en cuanto a la doctrina jurisprudencial, al menos la mayoritaria, ha quitado una de las vías más relevantes para obtener la eficacia del sistema jurídico laboral, la actuación de la administración laboral, dirigida en nuestro sistema por la Dirección del Trabajo.

Y que la actuación de la Dirección del Trabajo tenga tal objetivo, no constituye una particularidad de nuestro sistema, toda vez que la doctrina iuslaboralista del Derecho Comparado lo afirma tempranamente. Como afirma Otto KahnFreund, "...las leyes emanadas del Parlamento, por bien intencionadas que sean y bien hechas que estén, tiene escasa influencia para modificar las relaciones de poder entre trabajadores y empresarios." ${ }^{69}$. Dada la relación de desigual poder que se plantea en la relación de trabajo, difícilmente el trabajador podrá accionar por dicha eficacia. Y es por ello que los diversos sistemas nacionales han creado las Direcciones o Inspecciones del Trabajo, como entidad cuyo

${ }^{68}$ Considerando $4^{\circ}$ de Voto de Minoría, de Sentencia de la Excma. Corte Suprema, Rol 887 de 2008,12 de mayo de 2007, ya citada.

${ }^{69}$ Khan-Freund, O., Trabajo y Derecho, $3^{\text {a }}$ edición inglesa a cargo de Davés Paul: Freedland, Mark Traducción de Galiana Moreno, J., Ed. Ministerio del Trabajo y Seguridad Social de España, Madrid, 1987, p. 54. 
principal objetivo es velar por la eficacia de la normativa nacional a través del instrumento de la fiscalización.

Pues bien, de acuerdo a los últimos fundamentos que entrega la doctrina jurisprudencial mayoritaria, la Dirección del trabajo carecería de facultades para pronunciarse sobre las relaciones jurídicas contractuales, dado el "impacto" que ello provocaría en el sistema jurídico y económico.

Habría que entender, entonces, que las facultades fiscalizadoras de la Dirección del Trabajo sólo comprenderían contenidos normativos de dichas relaciones contractuales individuales. Si es así, habría que concluir que el entero fenómeno de la descentralización productiva y de sus diversas manifestaciones quedaría fuera de las competencias fiscalizadoras de la administración laboral, pues, precisamente, lo que efectúa este fenómeno es una nueva forma de organización de las empresas que en el ámbito de las relaciones de trabajos incide principalmente en los sistemas de contratación laboral y, en ello, en la definición del empleador.

Ciertamente que, en mi opinión, las manifestaciones concretas de la descentralización productiva no quedan fuera de dichas competencias fiscalizadoras de la Administración Laboral, como tampoco ha ocurrido en los demás sistemas de relaciones laborales, en cuanto uno de los principales desafíos que enfrentan ha sido precisamente velar por la eficacia de las normas del Derecho del Trabajo ante los desafíos que implica en tal sentido las diversas manifestaciones de la descentralización productiva.

Aunque en nuestro sistema está pendiente la construcción de la vía más relevante para lograr la eficacia de las normas laborales; éste no es otro que un sindicalismo fuerte, que en los diversos sistemas se ha manifestado como el mecanismo más eficaz en el logro de tal objetivo ${ }^{70}$.

\section{BibLIOGRAFíA}

Albornoz S., M. y otros, Subcontratación Laboral y Servicios Transitorios, Ed. LexisNexis, Santiago de Chile, 2007.

Dirección del Trabajo, Departamento de Estudios:

a. "Encla 2006, Informe de Resultados", Quinta Encuesta Laboral, Santiago de Chile, octubre del 2007.

b. "Encla 2004, Informe de Resultados" Cuarta Encuesta Laboral, Santiago de Chile, septiembre del 2005.

c. "Encla 2002 Informe de Resultados", Santiago de Chile, septiembre del 2003.

d. "Encla 99 Informe de Resultados", Santiago de Chile, 2000.

e. "Encla 98 Informe de Resultados Regiones", Santiago de Chile, 1999.

${ }^{70}$ Khan-Freund, Trabajo y Derecho, cit. nota n 70, pp. 54 y ss. 
ECheVerRía T., M. y otros autores, "El otro trabajo: el suministro de personas en las empresas", Cuaderno de Investigación $\mathrm{N}^{0} 7$, Dirección del Trabajo, Santiago, 2001.

Echeverría, M., "Los Riesgos Laborales de la subcontratación", Aporte al Debate Laboral, No 19, Departamento de Estudios de la Dirección del Trabajo, Santiago, abril de 2006.

FerRadA Bórquez, Juan Carlos, "El derecho fundamental a un juez predeterminado por la ley y potestades administrativas: notas a propósito del caso de la Inspección del Trabajo", Revista Estudios Laborales No 2, 2008.

KhAn-Freund, O., Trabajo y Derecho, Tercera edición inglesa a cargo de Davés, Paul; Freedland, Mark. Traducción de Galiana Moreno, J., Ed. Ministerio del Trabajo y Seguridad Social de España, Madrid, 1987.

Lizama Portales, Luis, "La Corte Suprema y el ejercicio de las facultades de los inspectores del trabajo en la ley de subcontratación: Una doctrina y dos consecuencias jurídicas posibles", Revista Estudios Laborales No 2, 2008.

Lizama P., L.; Ugarte C., J. L., Subcontratación y Suministro de Trabajadores, Ed. LexisNexis, Santiago 2007.

LÓPEz F., D., "Subcontratación laboral e igualdad salarial", Revista Laboral Chilena $\mathrm{N}^{\circ}$ 166, mayo, 2008.

Palavecino, C., Subcontratación. Régimen Jurídico del Trabajo Subcontratado y del Suministro de Personal, Editorial Jurídica de Chile, Santiago 2006.

Rojas M., I.; Aylwin CH., A., Los Grupos de Empresas en el Derecho Chileno del Trabajo, Ed. LexisNexis, Santiago, 2007.

UrzúA M., L., El vínculo de la subordinación o dependencia, como elemento del contrato de trabajo, Ed. LexisNexis, Santiago de Chile, 2004.

TAPIA G., F., "La necesidad de la reforma procesal laboral y previsional. Una constatación empírica", Anuario de Derecho del Trabajo y Seguridad Social № 2, 2001.

THAYER A., W., "Opinión tentativa para el caso de trabajadores de contratistas en las grandes empresas del Cobre", Revista Laboral Chilena No 163, enero, 2008. 